\title{
Nem Revolução Militar (RM) nem Revolução em Assuntos Militares (RAM), apenas mudanças de longa duração condensadas na guerra pelo gênio militar
}

\author{
Neither Military Revolution (RM) nor Revolution \\ in Military Matters (RAM), only long-lasting changes \\ condensed in the war by the military genius
}

\section{HÉCTOR LUIS SAINT-PIERRE LEANDRO JOSÉ CLEMENTE GONÇALVES}

\section{INTRODUÇÃO}

O final da Segunda Guerra Mundial trouxe consigo uma nova e dramática realidade: a mútua destruição assegurada (MAD) dos beligerantes e a possibilidade do extermínio atômico da vida sobre a Terra. A novidade nuclear provocou, entretanto, novas reflexões sobre a guerra e o seu futuro. Muitos "pensadores da guerra” (historiadores, filósofos, sociólogos, cientistas políticos, militares e políticos, entre outros) começaram a discursar sobre uma mudança radical na guerra, não somente de uma tensa e frágil paz para evitar a hecatombe nuclear, mas, fundamentalmente, de uma transformação na condução e realização das guerras do futuro. Surgia, então, uma nova categoria de análise, um novo conceito para explicar o fenômeno "guerra" - não somente para descrevê-lo, mas especialmente referido às transformações provocadas pelo emprego de uma tecnologia com potencial supostamente revolucionário da natureza da guerra no século XIV na Europa: a pólvora. As transformações de natureza tática, oriundas da introdução da arma de fogo, teriam implicado na exigência de um eleva-

Héctor Luis Saint-Pierre - Instituto de Políticas Públicas e Relações Internacionais Programa de Pós-Graduação “San Tiago Dantas”. Professor Titular da UNESP. Pesquisador PQ CNPq. Pesquisador FAPESP.

Leandro José Clemente Gonçalves - Doutor em História pela Unesp-Franca. Membro do Grupo de Estudos de Defesa e Segurança Internacional - GEDES. 
do padrão de disciplina e treinamento para o soldado comum, duas coisas praticamente inexistentes na Idade Média. Essa transformação levou, em 1955, ao surgimento do conceito de "Revolução Militar".

\section{REVOLUÇÃO MILITAR}

As primeiras pesquisas sobre Revolução Militar (RM) foram realizadas por historiadores britânicos interessados nas origens e desenvolvimento do Estado moderno e do absolutismo na Europa entre os séculos XVI e XVII. O grande pioneiro foi Michael Roberts que, em 1955, apresentou o conceito no artigo “The Military Revolution, 1560-1660". Roberts, um especialista em história sueca da Idade Moderna, argumentava que quatro elementos teriam desencadeado uma RM que levaria ao fortalecimento do Estado moderno. O primeiro foi uma revolução tática, com a substituição dos enormes quadrados de soldados, conhecidos por sua designação espanhola de tercios, armados de lanças longas (piques), por formações em linha de mosqueteiros, com armamento individual padronizado e custeado pelo Estado. O segundo elemento foi a "popularização" da cavalaria, graças ao fim das pesadas e caras armaduras e ao fato de o Estado pagar pelas montarias. O terceiro foi a manutenção de exércitos permanentes e profissionalizados em tempo de paz (era financeiramente inviável desativá-los nos períodos de inatividade, devido aos elevados custos para treiná-los e sustentá-los), o que transformou a ordem estratégica, pois exércitos permanentes e profissionais permitiam almejar objetivos mais ambiciosos, como a condução de campanhas simultâneas em um ou vários teatros de operações e a procura da decisão pela batalha. Por último, o impacto da guerra sobre a sociedade, tanto pelos custos tributários como pela convocação de homens produtivos para a guerra (Roberts 1995).

Roberts localiza as transformações táticas na Holanda, durante a Guerra dos Oitenta Anos (1568-1648), entre as Províncias Unidas dos Países Baixos e a Espanha governada pelos Habsburgos. O promotor destas transformações foi o príncipe Maurício de Nassau (1567-1625), auxiliado pelo seu primo, o conde João II de Nassau (1561-1623). Baseando-se em modelos táticos romanos antigos, os Nassau insistiram que suas tropas se exercitassem com a sapa (pá), tanto na construção de fortificações de campo (trincheiras, parapeitos, bocas de lobo, valas, entre outras) que pudessem abrigá-las e compensar sua inferioridade numérica frente ao Exército Espanhol da Flandres, quanto no assédio a cidades e fortalezas. Até o final do século XVI o entrincheiramento carregava consigo uma certa mácula de covardia, sendo que, quando necessário, alistavam civis para tal trabalho. Uma segunda mudança foi a introdução do treinamento em ordem-u- 
nida, sistematizando o regime de fogo com arcabuzes de mecha (que passaram a ser padronizados no calibre, facilitando a fabricação e a logística de distribuição da munição) ao obrigar seus soldados a realizarem o fogo por meio da contramarcha (que possibilitava que uma linha de frente de um batalhão realizasse um voleio, enquanto as linhas de trás remuniciavam suas armas para o próximo tiro, sustentando um regime de fogo contínuo sobre o inimigo). A terceira reforma foi a criação de unidades de infantaria menores, com batalhões de 550 soldados submetidos a um rigoroso programa de treinamento em quartéis e acampamentos. Em 1596 o conde João II contratou Jacob de Gheyn para desenhar um manual de exercícios para soldados arcabuzeiros (atiradores) e piqueiros (lanceiros) em batalha. O duro regime de treinamento e trabalho foi aceito pelos mercenários que serviam no exército holandês, pelos bons salários pagos regularmente. Por fim, como os oficiais precisavam educação formal para melhor adestrar a tropa nos complexos exercícios, o príncipe Maurício estabeleceu a primeira academia militar para oficiais em 1619 (McNeill 1982, 128-134).

A RM a que se refere Roberts teve continuação na Suécia de primórdios do século XVII, com as reformas do rei Gustavo Adolfo II. Gustavo substituiu o exército mercenário por uma força de camponeses conscritos (pagos com terras, remissões de taxas e em espécie), que por dois séculos foi a única do tipo na Europa, "o primeiro exército europeu verdadeiramente nacional”, fato que contribuiu para baratear os custos de um exército permanente (Roberts 1995,16$)$. A cavalaria voltaria a ter valor como arma de choque, só que carregando sobre o inimigo com espadas em punho, e sua artilharia teve o peso de suas peças reduzido para serem mais ágeis e manobráveis em campo (Roberts 1995, 14).

Depois da publicação do trabalho de Roberts, o debate sobre RM só ganhou um novo e revigorante impulso em 1976, com a publicação do trabalho “The Military Revolution, 1560-1660: A Mith?”, de Geoffrey Parker. Parker retrocede a análise de RM para o início do século XVI, com foco na Espanha dos Habsburgos, e atribuiu o constante crescimento dos exércitos europeus, entre os séculos XVI e XVII (Parker 2007, 41), ao desenvolvimento de uma fortificação resistente ao fogo da artilharia de cerco, as fortalezas construídas em traçado italiano. O próprio Parker explica as vantagens destas fortalezas, geralmente construídas num formato estelar:

as muralhas eram construídas cada vez mais baixas e de maior espessura; porém, isso implicava que os defensores, ainda que melhor protegidos contra o fogo da artilharia, já não conseguiam vigiar o terreno imediatamente abaixo e, por isso, se tornavam vulneráveis a um assalto de surpresa. Era, portanto, necessário um eficaz fogo de flanco, que só podia ser obtido construindo torres canhoneiras que se 
sobressaíssem num ângulo externo das muralhas e onde se instalava a artilharia, que não somente podia rechaçar um assalto às defesas principais, senão que também podia manter afastados os canhões de sítio inimigos e cobrir as zonas mortas dos bastiões vizinhos (Parker 2002, 36).

Parker foi muito além de Roberts. Baseando-se no trabalho de Daniel R. Headrick, "The Tools of Empire: technology and European Imperialism in the Nineteenth Century", de 1981, propôs, em 1988, que o domínio europeu sobre as populações e regiões não ocidentais foi uma consequência decorrente da RM europeia, que ele identificou entre 1500 e 1800 (Parker 2002, 28). Headrick defende que a superioridade tecnológica europeia (nos campos militar, farmacêutico e das comunicações) na era industrial foi a chave da conquista da África e da Ásia:

Os confrontos entre europeus e africanos depois de 1870 figuram entre os mais assimétricos na história. Para os africanos estes encontros trouxeram perplexidade e lutas sem esperança, enquanto para os europeus lembravam uma caçada mais do que uma guerra. Fuzis de retrocarga arruinaram a resistência africana tão decisivamente quanto a profilaxia do quinino superou a barreira da malária. Para ser correto, houve uma vasta gama de formas de encontros, do explorador isolado passando por uma aldeia até, no outro extremo, uma campanha militar de larga escala. Ainda assim, todos foram marcados pela qualidade das armas envolvidas (Headrick 1981, 115).

Também Parker e outros pesquisadores da RM acreditaram que a tecnologia superior das armas de fogo e do traçado italiano teriam garantido a superioridade europeia no mundo. Este fenômeno (a RM) seria um período de rápida mudança na condução da guerra, com resultados que mudariam o curso do desenvolvimento histórico muito além da esfera militar. Tratando da inovação arquitetônica do traçado italiano, Parker argumenta que tais fortalezas levaram a um forte impacto da guerra sobre a sociedade, pois sua grandiosidade exigia efetivos maiores, tanto para guarnecê-las quanto para sitiá-las, o que levou os Estados europeus a manter grandes contingentes de soldados, dilatar sua burocracia civil e melhorar os meios de arrecadação tributária para o custeio das obras de construção e sua preservação.

Muitos criticaram a tese de Parker, apontando eventuais equívocos e novas possibilidades de interpretação da RM. Clifford Rogers foi o pioneiro entre estes ao afirmar que a datação correta da Revolução seria o século XIV, durante o reinado de Eduardo III Plantageneta (1327-77) da Inglaterra, quando teria acontecido a "revolução militar eduardiana" que levaria à primazia da infantaria sobre a cavalaria, em particular por causa 
do arco longo inglês e do emprego de lanças longas (piques) entre as unidades de infantaria, ambos utilizados para deter/abater a cavalaria feudal francesa em batalhas como Crécy e Agincourt (Rogers 1995, 55-93). A peça central da inovação tecnológica plantageneta era o arco longo que, nas mãos de um arqueiro bem treinado, podia disparar mais rápido do que a besta, além de alcançar distâncias maiores com maior poder de impacto e penetração (Rogers 2001, 19). Paralelamente, os nobres cavaleiros de seu exército passaram a lutar, desde a batalha de Dupplin Moor (1332) contra os escoceses, a pé, utilizando suas lanças longas para manter a cavalaria inimiga em cheque e, dessa forma, proteger seus arqueiros e o restante de sua infantaria, que podiam abater os cavaleiros adversários com calma e em segurança (Rogers 2001, 26-28).

Outro crítico, talvez o mais ácido em relação ao trabalho de Parker, é Jeremy Black, que assenta a RM não em aspectos tecnológicos, mas na disciplina dos exércitos europeus. Black defende que somente após a superação de cisões religiosas europeias os governos puderam organizar e disciplinar seus exércitos. Assim, desde esta perspectiva, foi a mudança social de longa duração, transformadora mas não revolucionária, que possibilitou o melhor uso da tecnologia e não a tecnologia que viabilizaria a mudança social (Black 1995, 95-114). Black atentou especialmente para a questão do crescimento dos exércitos europeus, tão importante na teoria de Roberts quanto na de Parker. Para ele, os exércitos cresceram no século XVIII (sua especialidade) da mesma forma que haviam crescido no século XVII. Todavia, Black não se ilude, pois afirma que os oficiais exageravam o número de efetivos das tropas nos seus relatórios para ficar com pagamentos de soldados inexistentes (Black 1991, 7). Nem mesmo o elogio de Roberts e Parker às inovações táticas holandesas e suecas fica imune. Black mostra que durante a Guerra dos Trinta Anos (1618-1648), em particular nas batalhas campais de Nördlingen (1634) e Breitenfeld (1642), as táticas holandesas de pequenas unidades (batalhões) foram largamente superadas pelas táticas tradicionais dos tercios espanhóis e austríacos, destacando que a vitória geralmente terminava, no século XVII, nas mãos dos exércitos maiores, mais disciplinados e mais experientes, não nas dos mais inovadores (Black 1991, 12-13). Por fim, sobre a RM, diz que é mais

[...] adequado ver este processo como o complemento da competição internacional, em vez de argumentar que este levou a qualquer suposta revolução político-administrativa que produziu estados centralizados, burocráticos e autocráticos capazes de coagir a sociedade e dirigi-la a produzir os meios de destruição (Black 1991, 95). 
Mais recentemente, Mahinder S. Kingra questionou a perspectiva de Parker acerca do traçado italiano utilizando, como estudo de caso, a Guerra dos Oitenta Anos (1567-1648) entre Holanda e Espanha. Kingra escolheu este conflito por causa do foco de Parker sobre o Exército Espanhol de Flandres, além de se tratar de uma guerra centrada geográfica e cronologicamente na RM de Roberts e Parker e da guerra de assédios que se tornou uma constante neste conflito nos Países Baixos. Segundo seu argumento a tese de Parker não se sustenta. Diz ele que:

Em seus escritos de 1673, Raimundo Montecuccoli antecipou guarnições de apenas cem a quinhentos homens para a maioria das fortalezas bastionadas [...]. Sir Roger Williams, participante britânico na Guerra dos Oitenta Anos, calculou que uma guarnição de dois mil homens podia ser considerada uma força segura, "suficiente para guardar contra 10.000". Mais amplamente, em Della Architettura Militare (1599), Francesco de'Marchi notou que "por trás de bons muros uma pequena força podia desafiar uma hoste muito maior". [...] Como imaginado pelos arquitetos militares, teóricos e praticantes, então o trace italienne não estava orientado para abrigar grandes guarnições: em verdade, estava destinado a compensar a falta delas (Kingra 1993, 436-437).

Kingra ainda mostra que, na fase mais aguda do conflito, o príncipe Maurício de Nassau convenceu os Estados Gerais (governo da república holandesa) a aumentar o efetivo do seu exército de 30.000 soldados em 1620 para 128.877 em 1629 e que, nesta fase da luta, os holandeses não estavam construindo novos fortes que justificassem tal aumento de força, como imaginava Parker. O próprio Vauban, arquiteto e projetista militar do rei francês Luis XIV, não via a necessidade de aumentar os exércitos para guarnecer fortalezas. Pelo contrário: para ele as forças francesas se dilataram para atender "às demandas estratégicas criadas pela oposição militar unida contra a França” (Kingra 1993, 442).

Embora se possa discutir quando e onde ocorreram as RM ou mesmo se existiram, Stephen Morillo e Michael F. Pavkovic consideram que a disseminação dos trabalhos dos seus defensores e críticos foi salutar e teve o mérito de recolocar a História Militar no mainstream da História, restaurando gradualmente seu status acadêmico. Muitas outras supostas RM foram identificadas em períodos anteriores ou posteriores, como na Antiguidade, no mundo medieval ou mesmo na era contemporânea (Morillo and Pavkovic 2006, 73-76). Vejamos agora algumas das supostas RM.

Para Roberts, Parker e outros pioneiros do estudo da RM, as reformas militares introduzidas na Espanha, por volta de 1500, pelos nobres da ca- 
sa de Nassau na República Holandesa, e por Gustavo Adolfo no reino da Suécia, entre o final do século XVI e início do século XVII, teriam levado à constituição de imensos exércitos profissionais e permanentes e, com isso, a um maior impacto da guerra sobre a sociedade, seja pelas desgraças da guerra ou pelos pesados impostos para sustentar o aparato militar, o qual, por sua vez, demandou uma imensa burocracia civil para gerenciar as questões administrativas e logísticas relativas às instituições militares e, por tudo isso, ao nascimento e fortalecimento do Estado moderno.

Tais exércitos, constituídos muito mais por infantaria do que por cavalaria, com seus gastos com armamentos, equipamentos, provisões, transportes, uniformes, alojamentos e treinamento custeados pelo Estado tornaram-se cada vez mais onerosos e difíceis de administrar. Colocavam, assim, uma enorme pressão sobre a burocracia civil que, por sua vez, precisava dilatar seu quadro de funcionários para a administração militar e a arrecadação de tributos necessários à manutenção daquelas forças na paz ou na guerra. Por fim, o contingente destes exércitos constituído, principalmente, por mercenários, aumentava a pressão sobre o Estado e a opressão deste sobre a sociedade para coletar impostos. Assim, a primeira RM teria conduzido ao nascimento do Estado moderno, ao fortalecer seu aparato burocrático civil e militar, reforçando ainda mais a centralização que desembocaria, como resultado final, no Absolutismo.

A Revolução Francesa (1789-99) e a precedente Revolução Americana (1775-81), tornaram possível os exércitos de massas de conscritos. Contra estes exércitos, as monarquias absolutistas eram capazes de colocar em campo apenas seus exércitos permanentes e profissionais de mercenários (geralmente estrangeiros) que, embora fossem considerados grandes para os padrões dos séculos XVII e XVIII, resultavam pequenos quando comparados aos enxames de franco-atiradores da Revolução Francesa.

O Grande Exército napoleônico, assim como o próprio Napoleão, foram subprodutos da Revolução de 1789. A resposta continental a este desafio - e pode-se dizer assim porque a Inglaterra insistiu até a Primeira Guerra Mundial em sustentar um pequeno exército profissional, recusando-se a adotar o sistema de conscrição universal masculina - foi decorrência, principalmente, das campanhas napoleônicas na Espanha (1808-14), da Rússia (1812) e da Prússia (1813). Estas campanhas produziram uma transformação que Clausewitz rotulou como uma "guerra moderna" por engendrar o "armamento do povo". Nas suas próprias palavras:

os espanhóis mostraram [...], pela sua luta encarniçada, que o armamento geral da nação e as medidas insurrecionais podem produzir efeito numa grande escala [...]; do mesmo modo, a Rússia ensinou-nos, através da sua campanha de 1812, em primeiro lugar, que 
um império de vastas dimensões não pode ser conquistado $[\ldots] \mathrm{e}, \mathrm{em}$ seguida, que a probabilidade de êxito final não diminui sempre na medida em que se perdem as batalhas, as capitais e as províncias [...]. Além disso, a Prússia (1813) mostrou que os esforços súbitos podiam aumentar seis vezes mais as forças de um exército graça à milícia, e que esta milícia está igualmente apta ao serviço no exterior como no seu próprio país. Finalmente, estes acontecimentos mostraram todos o enorme fator que o coração e o sentimento de uma nação podem representar na produção das forças do Estado, na guerra e no combate, e, agora que os governos aprenderam a conhecer todos esses meios adicionais, não se deve estar à espera de que os deixem inativos em guerras futuras (Clausewitz 1996, 245-6).

Assim a grande RM desencadeada pela Revolução Francesa seria marcada pela mobilização em massa (levée en masse) de enormes contingentes da população, animados pelo fervor patriótico, fazendo com que o fenômeno da guerra não fosse mais considerado como um assunto de interesse exclusivo dos monarcas mas, antes, como algo de interesse direto do povo.

A Revolução Industrial, por seu turno, tornou possível transportar, armar, vestir e alimentar eficientemente aquelas massas de soldados. Ao longo do século XIX, a industrialização cobriu a Europa e a América do Norte com ferrovias que aceleraram o deslocamento de exércitos cada vez maiores por distâncias ainda mais dilatadas do que aquelas cobertas nas campanhas militares dos séculos XVII e XVIII, condicionando a estratégia, como nos mostra Martin Van Creveld:

Já durante a década de 1850 , os franceses se empenharam na construção de uma malha ferroviária projetada especificamente para fins militares, que lhes foi muito útil na guerra de 1859 contra a Áustria. Não fossem os trilhos e os fios, a guerra civil dos Estados Unidos teria sido inconcebível. O conflito de 1861-65 merece, de fato, a denominação de primeira guerra Ferroviária, já que a movimentação de ambos quase sempre dependia da disponibilidade de trilhos […] ou tinha como fim destruir os trilhos do inimigo [...]. Só as ferrovias viabilizaram para os Federais a convocação de nada menos que 2 milhões de homens durante o conflito, façanha que, com uma população de apenas 27 milhões de habitantes dispersos por um país vastíssimo, não tivera paralelos até então (Creveld 2004, 359-360).

Dotar os soldados com moderno armamento pessoal, fardamento diversificado para as diferentes estações do ano e alimentos em conserva e desidratados em abundância de calorias para satisfazer as demandas logísticas exigidas por longas e prolongadas campanhas só foi possível gra- 
ças às modernas e ágeis indústrias bélicas, têxteis e alimentícias e ao seu fabuloso desenvolvimento. A Revolução Industrial também viabilizou comunicações de longo alcance, sustentadas pelo telégrafo elétrico, e a total transformação das marinhas da era da vela às modernas esquadras de encouraçados movidos a vapor e, pouco depois, pela eletricidade e o diesel (Reid 1999, 16-31).

As guerras do final do século XIX e da primeira metade do século XX incorporaram elementos das RM precedentes, porém lançaram os fundamentos de uma nova transformação, segundo seus advogados. Se nas guerras do século XIX a ferrovia era um elemento condicionador do planejamento estratégico terrestre, a mobilidade conferida aos exércitos na forma do motor a combustão interna e na constituição de forças mecanizadas e blindadas libertaria os planejadores das amarras ferroviárias. Simultaneamente, a guerra alcançaria, ainda, as dimensões aérea e submarina, tornando-se tridimensional.

Ao introduzir o bombardeio aéreo-estratégico contra os centros urbanos industrializados, durante a Segunda Guerra Mundial, e o ataque submarino aos comboios de suprimentos, as guerras mundiais intensificaram o impacto direto da guerra sobre a sociedade e vice-versa, dado que o objetivo era causar o esgotamento social por meio da fome e das demais formas de privação, para levar à oposição popular à guerra e, dessa forma, ao enfraquecimento do esforço de guerra.

A guerra, neste contexto, foi, porém, marcada pela luta convencional entre forças simétricas — quase sempre com o mesmo equipamento, treinamento e comportamento do comando. Embora tenham ocorrido algumas experiências de guerra assimétrica durante e entre as duas guerras mundiais, esta modalidade só alcançaria a apoteose teórica e operacional nos conflitos mal chamados de "baixa intensidade" da era nuclear.

Podemos distinguir, nitidamente, dois tipos de conflitos no período colocado entre 1945 e a primeira década do século XXI: o conflito convencional, interestatal - como as guerras árabes-israelenses de 1967 e 1973, a guerra Irã-Iraque, a guerra das Malvinas (1982), os conflitos do Golfo (1991), a guerra do Cenepa entre Equador e Perú (1995) e a invasão do Iraque (2003) - e as guerras assimétricas de $4^{\mathrm{a}}$ geração, que vêm ganhando ímpeto desde a Revolta Árabe contra a Turquia na Primeira Guerra Mundial, passando pela "guerra popular prolongada" maoísta e as guerras afro-asiáticas de libertação nacional até os atuais embates entre forças convencionais ocidentais e milícias islâmicas no Iraque e no Afeganistão.

Imaginava-se, no final da década de 1940, que os artefatos bélicos nucleares inaugurariam uma era duradoura de paz, de tensa paz, baseada no terror nuclear entre as potências, pois, em virtude de seu avassalador poder 
destrutivo, anulariam a lógica da imposição da vontade ao vencido pela mútua destruição assegurada. Contudo, houve uma explosão de conflitos assimétricos entre forças não convencionais e as de ordem mais convencional, como no Vietnã (1945-1975) e no Afeganistão (1979-1988).

Nesse sentido, concordamos com Thomas X. Hammes (2006, 2):

A guerra de quarta geração $(\mathrm{G} 4 \mathrm{G})$ usa todas as redes - política, econômica, social e militar - disponíveis para convencer os tomadores de decisões políticas do inimigo de que seus objetivos estratégicos são inexequíveis ou muito custosos para os benefícios perceptíveis. [...] Ainda enraizada na percepção fundamental de que uma vontade superior, quando adequadamente empregada, pode derrotar um poder militar e econômico maior, a $\mathrm{G} 4 \mathrm{G}$ faz uso das redes sociais para conduzir sua luta. Diferente das gerações anteriores de guerras, ela não tenta vencer derrotando as forças militares inimigas. Em vez disso, via redes, ela ataca diretamente as mentes dos tomadores de decisão adversários para destruir a vontade política do inimigo. As guerras de quarta-geração são longas - medidas em décadas mais do que em anos.

\section{A NEGAÇÃO DA REVOLUÇÃO MILITAR}

Destarte a abundância de críticas aos trabalhos de Roberts e Parker, reconhecemos que a maioria delas se utiliza do conceito de RM, apenas conectando-a com outras épocas ou outras tecnologias militares e/ou civis, com possibilidade de empregos bélicos que não apenas aquelas identificadas nos textos daqueles dois historiadores. As críticas se orientam mais a discutir a datação da origem da RM mas que sua própria essência.

Uma nova vertente de historiadores busca analisar a guerra dentro de um contexto da "longa duração" braudeliana, questionando o fenômeno enquanto revolucionário. Deixando de lado a caraterização revolucionária, esta vertente enfatiza permanências, regressos e reconhece uma evolução lenta e gradual do fenômeno da guerra, recusando determinismos tecnológicos como desencadeantes da transformação da e na guerra. Estes historiadores negam a transformação revolucionária da guerra e refutam o uso do conceito de RM para explicar as mudanças ao longo da história. Tal vertente pode ser rastreada desde a publicação de Warfare in the Seventeenth Century, de John Childs, em 2001. O autor argumenta que os "novos exércitos” europeus, constituídos entre os séculos XVI e XVII, não configuravam uma modernidade, dado que o serviço militar não era um requisito para o exercício da cidadania (como os exércitos nacionais nascidos a partir da Revolução Francesa), sendo forças tão mercenárias quanto os exércitos 
medievais, só que mais permanentes. Childs (2001, 208-210) também frisa que o fato das comunicações serem ruins e "excepcionalmente lentas", as operações ficarem limitadas a uns poucos teatros europeus (em especial Flandres, Renânia e Itália setentrional) e os exércitos dependerem de vias fluviais para seu deslocamento fazia com que "nada nos campos da estratégia e das operações fosse revolucionário ou moderno”. No campo da tecnologia de armamentos de fato ocorreram mudanças. As lanças longas (ou piques), foram substituídas na infantaria pelas baionetas no final do século XVII, a cavalaria voltou a ser usada como arma de choque na perseguição e eliminação das forças inimigas já batidas, uniformes foram adotados na maioria dos exércitos europeus e, por fim, tanto os exércitos quanto as burocracias civis cresceram muito. Para Childs, contudo, "nenhuma destas mudanças contou como uma Revolução Militar ou deu origem ao moderno" (Childs 2001, 11).

Em 2016, Frank Jacob e Gilmar Visoni-Alonzo (2016, 1) desferiram uma crítica ainda mais pesada contra os defensores da RM. Para eles, Parker (e outros que lhe foram posteriores) construiu uma artificialidade que lhe facilitava explicar as causas da dominação ocidental na era do colonialismo (entre 1500 e 1800), por meio de vantagens tecnológicas, como as armas de fogo e as fortalezas construídas em traçado italiano, mas sem apresentar evidências históricas que comprovassem sua perspectiva. Já na abertura de seu trabalho, Jacob e Visoni-Alonzo anunciam sua intenção: "pedimos que o conceito de Revolução Militar seja inteiramente repelido. Tais revoluções são mitos [...] nos parece inútil continuar com um modelo que é derivado mais de um preconceito eurocêntrico do que do fato histórico" (Jacob and Visoni-Alonzo 2006, 2).

Esses historiadores buscam provar que o sucesso espanhol nas conquistas do México e do Peru no século XVI deveu-se sobretudo às dissenções entre as populações indígenas, a uma diplomacia junto aos povos indígenas eficientemente conduzida, aos pactos com as elites locais e às doenças europeias desconhecidas na América. $\mathrm{O}$ pequeno exército (550 homens, sendo 17 a cavalo) de Hernán Cortez no México, por exemplo, quase não contava com armas de fogo portáteis, e dispunha de somente dez peças de artilharia, tendo sua infantaria quase toda armada com escudos, espadas, lanças e bestas, ou seja, uma força dotada tanto de armas brancas quanto seus oponentes astecas. Logo, sem o apoio logístico e humano (com efetivos para o combate) de seus aliados índios (totonacs e tlaxcalas), Cortez teria muita dificuldade em alcançar a conquista dos astecas, que não configuraria um caso de superioridade da RM europeia:

Enquanto Cortez e Pizarro eram indiscutivelmente figuras da Renascença e heróis maquiavélicos (ou vilões, dependendo da pers- 
pectiva), seus empreendimentos militares não se adequam dentro da estrutura da Revolução Militar, como conceitualizada por Roberts e Parker [...] As estratégias, métodos operacionais e táticas que Cortez e Pizarro utilizaram na conquista do México e do Peru não são reproduzíveis; elas foram o produto de circunstâncias históricas ligadas a contextos políticos, tecnológicos, geográficos e cronológicos muito específicos [...] não há lições táticas específicas emanando de sua campanha militar que pudessem ser aplicadas ao teatro europeu. Consequentemente, a conquista espanhola do Novo Mundo é um exemplo que mostra que o relacionamento entre tecnologia superior e supremacia europeia nem sempre era evidente (Jacob and VisoniAlonzo 2006, 36).

Paralelamente, mostram que na Ásia, onde governos e populações locais tinham fácil acesso a armas de fogo (tanto portáteis quanto artilharia pesada localmente produzidas), em alguns casos consideradas até de qualidade superior às fabricadas na Europa da época, o domínio colonial não poderia resultar de uma "superioridade tecnológica", ali inexistente. Neste continente, a penetração europeia se deu de maneira muito mais lenta, e só alcançou êxito porque a diplomacia dos governos europeus foi eficiente em explorar, como na América, as lutas e dissenções internas. Citando o relatório do vice-rei português na Índia, Alfonso de Albuquerque (1453-1515), os historiadores mostram que os "os governantes indianos já possuíam poderosas fortalezas e canhões e armas de fogo bem produzidas”. E, ainda, que

Os inimigos indianos eram tudo menos fracos e despreparados. No começo do século XVI, a indústria de armas de fogo de Goa era uma das melhores do mundo [...]. O vice-rei português Albuquerque enviou para Portugal alguns mosquetes de mecha que deviam destacar a qualidade dos armeiros indianos, que não ficavam atrás de suas contrapartes boêmias daquela época. [...] Parece altamente pertinente, portanto, destacar a importância da assistência nativa de que necessitavam as potências europeias para estabelecer o controle colonial. Como mostra o caso indiano, não foram tecnologias militares superiores que asseguraram o domínio dos invasores europeus. Como visto no caso do império asteca, muito mais decisivos foram os conflitos existentes, que permitiram que as potências coloniais usassem as rivalidades e tensões entre as elites locais para seus próprios fins. Ademais, os invasores europeus [...] só puderam ser bem-sucedidos pelo uso de tropas auxiliares nativas para alcançar uma igualdade numérica com os inimigos que eles tinham que enfrentar. Uma Revolução Militar não foi, portanto, a razão para a supremacia do poder europeu no subcontinente indiano (Jacob and Visoni-Alonzo 2006, 38-39). 
Além de não considerarem que a transformação se dá de maneira revolucionária a partir da introdução de uma ou várias novas tecnologias, a mudança, lenta e gradual, é motivada pela presença de uma séria ameaça externa. Citando os casos históricos não europeus da Índia, das guerras feudais japonesas da era Sengoku (entre meados do século XV e o final do século XVI da era cristã), da invasão japonesa liderada por Toyotomi Hideyoshi na Coreia e do Império Otomano ameaçado tanto por interesses europeus quanto persas no século XVII, mostram que as ameaças externas estavam na raiz da necessidade de modernizar o recrutamento e o treinamento, expandir os efetivos e equipar melhor as tropas, invalidando o argumento eurocêntrico de Parker (Jacob and Visoni-Alonzo 2006, 36). Por fim, a "Revolução Militar" de Roberts, pautada em exércitos de infantaria de piqueiros não era inovadora, mas, antes, baseada numa releitura renascentista do modelo macedônico de falange, uma força de infantaria que contava com a sarissa, uma lança tão longa quanto o pique, como sua arma principal (JACOB, F. VISONI-ALONZO, G. 2006, p. 36). Totalmente diversa em relação ao conceito de RM é a origem do conceito de Revolução em Assuntos Militares (RAM), apesar de ser um conceito recentemente apropriado pelos historiadores.

\section{REVOLUÇÃO EM ASSUNTOS MILITARES}

Em meados dos anos 1970, o Departamento de Defesa (DoD) dos Estados Unidos e seus congêneres da OTAN preocupavam-se em compensar a vantagem numérica das forças convencionais da União Soviética e seus aliados do Pacto de Varsóvia, não somente com artefatos nucleares, mas especialmente com armamento convencional de tecnologia de ponta. Em 1976, o secretário americano de defesa, Harold Brown, acreditava ter encontrado a resposta para este problema numa "estratégia de compensação" que apostaria todas as suas fichas na tecnologia para superar a vantagem esmagadora das forças comunistas. Entre os dispositivos de alta tecnologia então vislumbrados pelo DoD estavam os aviões invisíveis aos radares (stealth), novos sistemas eletrônicos de comando, controle, comunicações e inteligência (sintetizados na sigla C3I) e munições guiadas de alta precisão (popularmente chamadas "armas inteligentes").

Os soviéticos, que naquele então baseavam sua estratégia para uma eventual guerra europeia numa ofensiva blindada em larga escala, contando com suas próprias forças e as de seus aliados europeus orientais, passaram — principalmente graças aos estudos desenvolvidos pelos chefes do estado-maior geral Nikolai Ogarkov (1977-84) e Sergei Akhromeyev (1984-88) — a apreciar esta transformação tecnológica como uma "Revolução Técnico-Militar". 
A doutrinação marxista-leninista do corpo de oficiais do Exército Vermelho em suas academias militares lhes permitia uma imensa receptividade ao conceito de revolução nos meios militares. Mesmo com os expurgos stalinistas de 1937, o conceito de Revolução Militar vingou, em grande parte devido ao choque causado pela Blitzkrieg de 1941 e pela incorporação de munição guiada de precisão, desde 1970, por parte das forças armadas americanas. Isto sugeriu aos pensadores soviéticos que uma revolução tecnológica estava ocorrendo [...]. Dada sua atenção — baseada em ideologia aos fatores materiais, os soviéticos focaram sobre aspectos tecnológicos do que eles percebiam como uma "revolução técnico-militar" emergente (Knox and Murray 2008, 2-3).

Em 1993, após o estrondoso sucesso daquelas novas tecnologias sobre as forças convencionais iraquianas de Saddam Hussein na Guerra do Golfo (1991), o analista norte-americano de defesa Andrew Marshall cunhou o termo "Revolução em Assuntos Militares" (ou RMA, do inglês Revolution in Military Affairs), derivando-o do conceito de Revolução Técnico-Militar soviético, para descrever as transformações desencadeadas pelas novas tecnologias de informação sobre a tática, doutrinas e estrutura das forças armadas. Enquanto os soviéticos compreendiam a transformação como um produto da inovação tecnológica, Marshall percebia que somente a tecnologia não seria suficiente para desencadear a mudança. Era preciso também “desenvolver novas doutrinas e procedimentos de emprego, táticas e formas de organização para que as novas armas pudessem demonstrar seu alcance real" (Knox and Murray 2008, 4).

Piella Colom (2008, 42) define a RAM afirmando que se trata de

[...] uma transformação na forma de operar dos exércitos, de consequências estratégicas, que pode produzir-se quando se integram e exploram novas tecnologias, táticas, doutrinas, procedimentos ou formas de organização [...] também se tem comentado que existe uma certa tendência em identificar estas revoluções como a consequência lógica da invenção de novas armas mais letais ou eficientes, contudo, a experiência histórica demonstra que os avanços tecnológicos por si dificilmente podem provocar uma mudança desta natureza ou alcance. Efetivamente, para que um desenvolvimento tecnológico possa resultar numa RAM, não somente é necessário transformar as estruturas, procedimentos e táticas militares, senão também a ideologia e práticas do coletivo castrense, que deve substituir os velhos costumes por novas técnicas, métodos e estilos de comando e controle das operações. Em outras palavras, a tecnologia é um elemento necessário, porém, insuficiente para explicar a gênese das Revoluções em Assuntos Militares. 
Logo, enquanto a RM seria uma transformação de amplo escopo nas relações entre Estado, sociedade, economia e forças armadas, a RAM ocorreria apenas no ambiente propriamente militar, conduzindo às novas formas de combate. Para os teóricos adeptos da ideia de RAM, esta pode ser tanto uma consequência de uma RM de amplo alcance quanto um elemento desencadeador de uma RM.

Em 1994, um artigo na prestigiosa publicação Joint Force Quaterly (JFQ) sumarizava a RAM da seguinte maneira:

A transformação tecnológica pode revolucionar a guerra no próximo século. As nações que explorarem as emergentes tecnologias através de uma doutrina operacional inovadora e da adaptação organizacional podem obter ganhos significativos relativamente à eficiência militar. No passado, os Estados Unidos tiveram tempo suficiente para adaptar-se em meio a guerra às revoluções militares que se desenvolveram na paz. Entretanto, a proliferação da tecnologia pode não mais permitir o luxo de observar os desenvolvimentos desde a via lateral. O papel dos militares no desenvolvimento de conceitos para explorar as tecnologias emergentes será crucial para permanecermos à frente dos competidores. Os oficiais subalternos em particular precisam ser encorajados a pensar sobre implicações da emergente revolução em assuntos militares (Fitzsimonds and Van Tol 1994, 24).

Logo, os autores do artigo e a linha editorial deste periódico diretamente ligado ao DoD dos Estados Unidos compreendiam a RAM como um subproduto do progresso tecnológico. Autores mais recentes, todavia, não adotam livremente a perspectiva da RAM exclusivamente condicionada pela tecnologia, notando que esta seria apenas uma entre suas diversas facetas. Para estes, a RAM é uma "mudança de paradigma na natureza e conduta das operações militares”, Richard O. Hundley percebeu outras características definidoras das RAM: 1) geralmente são produzidas por atores não dominantes no cenário mundial, sendo um caso exemplar o desenvolvimento da Blitzkrieg pelos militares alemães, derrotados e desacreditados em 1918; 2) atribuem uma enorme vantagem militar aos atores que as exploram primeiro, caso do arco longo usado pelo ingleses na Guerra dos Cem Anos; 3 ) rendem dividendos às nações que não inventaram uma tecnologia inovadora, exemplo da metralhadora Gatling, desenvolvida nos Estados Unidos na década de 1860, mas usada com grande impacto por ingleses e franceses na África a partir da década seguinte; 4) não são condicionadas somente pela tecnologia, caso das guerrilhas americanas contra os ingleses na Guerra de Independência dos EUA, que não faziam uso de tecnologia diferente da dos britânicos; 5) aquelas RAM que implicam em novas tecnologias o fizeram a partir da combinação de várias tecnologias 
e não somente a partir de uma, novamente vem à mente o exemplo da Blitzkrieg, que combinava a velocidade e o poder de fogo do avanço terrestre com ampla superioridade aérea; 6) as RAM condicionadas pela tecnologia não o foram somente a partir de novas armas, como nos exemplos do emprego do telégrafo e da ferrovia nas guerras de meados do século XIX; 7) as RAM impulsionadas pela tecnologia são compostas por três elementos: a tecnologia, a doutrina e a organização; 8) demandam muito tempo para render frutos concretos; 9) sua utilidade militar é frequentemente controversa e duvidosa até o momento em que se prova em combate (Hundley 1999, 11-17). Obviamente os apologistas da RAM acreditam que cada uma destas características pode ser historicamente comprovada.

A primeira característica pode ser exemplificada analisando-se o caso do tanque de guerra entre as duas guerras mundiais. Embora tenha sido empregado pioneiramente pelos ingleses durante a Grande Guerra de 1914-1918, foi em mãos alemãs, entre as décadas de 1920 e 1930, e utilizando-se de simulacros feitos em lona e "motorizados" com bicicletas, devido às restrições impostas pelo Tratado de Versalhes de 1919, que se desenvolveu uma doutrina operacional funcional que, ao longo da Segunda Guerra Mundial (1939-1945), seria copiada pelos aliados.

As segunda e terceira características levantadas por Hundley podem ser exemplificadas pelo poder nuclear, dado que o domínio norte-americano nesta área garantiu um imensa vantagem aos Estados Unidos até, pelo menos, 1949, quando os soviéticos anunciaram também possuir esta tecnologia e, no segundo caso, pela metralhadora, que, embora sendo uma invenção americana, foi utilizada primeiramente pelos europeus em sua conquista neocolonial da África.

A Guerra de $4{ }^{\mathrm{a}}$ Geração, também conhecida como Guerra Assimétrica, corrobora a quarta característica, pois os recursos tecnológicos empregados pelas forças de resistência (geralmente guerrilhas) contra seus poderosos adversários são extremamente rudimentares, sendo que para a resistência o importante não é a vitória tática imediata, mas o desgaste prolongado do inimigo e negar-lhe a vitória. Como exemplos disso poderíamos citar os atuais casos das guerras no Iraque e no Afeganistão.

Retornamos, agora, à Blitzkrieg alemã para nos referirmos à quinta característica. O tanque não foi, sozinho, a chave do sucesso nazista no início da Segunda Guerra Mundial. Seu emprego atingiu o sucesso ao combinar o fogo rápido e a superioridade aérea fornecida pela Luftwaffe (força aérea), compondo, assim, uma RAM tecnológica desencadeada por um sistema combinado de armas e tecnologias de comunicação de ponta, e não somente por uma tecnologia isolada. 
O emprego do telégrafo visual Chappé pelos franceses durante as eras revolucionária e napoleônica, entre 1792 e 1815, e do telégrafo elétrico, da ferrovia e do balonismo nas guerras da era industrial (Crimeia 185356, Secessão Americana de 1861 a 1865, Paraguai entre 1864 e 1870 e Unificação Alemã de 1864 a 1871), atestariam a veracidade da sexta característica, pois seriam todas elas tecnologias de uso e origem civil.

As aeronaves combinadas com navios porta-aviões levaram a uma inovadora combinação tecnológica que, por sua vez, produziu uma nova doutrina de guerra naval que ressaltava o combate além do alcance da visão dos artilheiros. Esta novidade obrigou as esquadras que empregavam tais tecnologias a adotarem o princípio organizacional das frotas combinadas, dotadas de diferentes tipos de belonaves e capitaneadas, geralmente, por um porta-aviões, exemplificando assim a décima característica.

Por fim, as oitava e nona características podem ser constatadas, também, no exemplo dos porta-aviões. Seu desenvolvimento até o amadurecimento e eficiente emprego (pelos ingleses contra a base naval italiana de Taranto, em 1940, e pelos japoneses contra a base americana em Pearl Harbor, em 1941), demandou cerca de três décadas e só teve sua validade comprovada depois de muita controvérsia entre políticos, estados-maiores militares, imprensa e opinião pública, particularmente nos Estados Unidos e na Inglaterra.

Aqueles teóricos estadunidenses da RAM que estavam firmemente aferrados à ideia de transformação pela tecnologia não perceberam, ou não quiseram admitir que a mera presença de um novo artefato militar, ou de origem civil com potencial emprego militar, em uma organização armada não a tornaria per se moderna. Na verdade, também precisa haver, juntamente, o desenvolvimento coerente de uma nova doutrina operacional e uma adequada organização para dar-lhe um emprego realmente eficiente. As forças iraquianas dos anos 1980 estavam entre as mais sofisticadas do Oriente Médio em matéria de equipamentos. Todavia, sua doutrina operacional e sua organização lembravam as das forças europeias da Primeira Guerra Mundial. No final do século XIX, as forças ashantis e zulus conseguiram capturar várias peças de armamento moderno inglês em suas guerras contra a dominação neocolonial; contudo, não desenvolveram uma doutrina operacional e uma organização coerentes com aquelas armas e acabaram sendo subjugadas. $\mathrm{O}$ caso dos zulus é particularmente ilustrativo. Após destroçarem uma força britânica/sul-africana de cerca de 1.200 homens na batalha de Isandlawana (22/01/1879) e capturarem farta quantidade de armas e munições, atacaram com elas um pequeno destacamento inglês com cerca de 120 soldados no posto de Rorke’s Drift, a 10 quilômetros de Isandlawana, com um resultado completamente diferente (351 zu- 
lus mortos frente a 15 mortos e 12 feridos britânicos que, mais importante ainda, conseguiram resistir e derrotar a força zulu de aproximadamente 4 mil guerreiros) (Hanson 2002, 397-424).

Posto de outra forma, podemos afirmar que os britânicos, dotados de tecnologias superiores, foram derrotados em Isandlawana por conta de um dispositivo tático que havia espalhado 1.200 soldados bem treinados por cerca de 1,6 quilômetros de linha defensiva, impossibilitando a concentração de fogo dos seus oponentes pela dispersão da tropa zulu. Já em Rorke’s Drift, nos dias 22 e 23 de janeiro de 1879, a pequena guarnição britânica, embora completamente sitiada, contava com uma razoável fortificação de campo improvisada, defendia um perímetro bastante reduzido, também estava equipada com o mortífero fuzil Martini-Henri, porém utilizou suas armas da maneira prescrita nos regulamentos e doutrina de fogo ensinados no treinamento do exército britânico, ao passo que os zulus equipados com fuzis capturados aos mortos de Isandlawana disparavam suas armas isoladamente, sem disciplina ou doutrina coerentes com seu uso. Para Victor Davis Hanson (2002, 424), os zulus não tinham

[...] experiência como uma força de fuzileiros que miravam, atiravam e recarregavam armas de fogo modernas obedecendo a comandos e, quando atiravam individualmente, faziam-no de acordo com protocolos rígidos em relação ao alcance e à natureza do alvo.

Dessa forma, a tecnologia, por si, não é suficiente para mobilizar qualquer transformação, como querem os defensores das RAM porque as condições de combate, ou o emprego de tropas insuficiente ou inadequadamente treinadas, muitas vezes impedem a sua mais eficiente aplicação. Ademais, toda vantagem tecnológica pode ser negada por meio da inteligente aplicação de recursos os mais simples como contramedidas baratas (em custos, não necessariamente em vidas humanas) e eficientes, como durante a Guerra do Vietnã (1964-1975), quando, buscando superar a vantagem do poder aéreo esmagador dos Estados Unidos, o general norte-vietnamita Vo Nguyen Giap ordenou que suas tropas lutassem o mais próximo possível das forças terrestres americanas, de forma que estas ficassem impossibilitadas de chamar apoio aéreo pesado para esmagar os vietnamitas. Giap sintetizou essa tática na máxima "agarrem na cintura do inimigo para combatê-lo” (Wilkins 2011, 21). O general Nguyen Chi Thanh, subordinado a Giap, explicou de maneira mais detalhada o funcionamento desta tática em sua relação com a necessidade de superar as vantagens tecnológicas do inimigo quando disse:

Sempre assuma o controle, escolha a melhor localidade e o tempo mais propício para a batalha; force o inimigo a lutar nossa pró- 
pria batalha da nossa maneira; sempre ataque e mova-se, concentre e disperse ritmicamente, cobertura, camuflagem, ocultação e disfarce bem, usando subterfúgios para enganar o inimigo; combata a curta distância e rápido, lute ferozmente, termine a luta rapidamente (uma batalha deve durar apenas entre 15 e 20 minutos, uma campanha deve durar apenas de três a cinco dias); e o comandante precisa compreender bem a topografia do campo de batalha, ele deve ir ao local exato para estudar o terreno e compreende o modus operandi de seu inimigo, ele deve antecipar a condução da batalha usando diferentes planos, concentrando seu poder de fogo e abrindo fogo de uma alta elevação para superar o inimigo (Wilkins 2011, 22).

Por fim, acreditamos, também, que o argumento da RM é inviável, pois, dependendo do autor, as transformações que esta historiografia apresenta se dão num espaço temporal tão longo que não poderiam ser tratadas como revoluções, mas, antes, como processos evolutivos de longa duração. Por fim, os "modernistas" britânicos, propositores da Revolução do Armamento Raiado, vista como apenas mais uma RAM por importantes teóricos estadunidenses desta vertente, estão também equivocados. Em realidade, as novas tecnologias de armas raiadas não foram capazes de modificar a doutrina de emprego nem a tática e, menos ainda, a estratégia. Assim, muito antes de ter provocado uma revolução ou de ser fruto de uma ampla revolução, a Guerra Civil Americana está inserida num contexto de uma lenta e gradual evolução que teve início com a introdução da pólvora nos exércitos do século XV. Não há rupturas revolucionárias na história da guerra, há sim uma longa história de desenvolvimento e paulatina incorporação de paulatina incorporação de meios meteriais, de doutrinas de emprego dessas inovações, de alterações da ordem tática que aproveita aquelas doutrinas, tudo isso numa história evolutiva dinamizada pelos enfrentamentos nos quais prevalece o lado beligerante que melhor consegue adaptar sua estratégia, sua tática e seu emprego dos meios adequadamente às exigências conjunturais do combate. Em outras palavras, a arte da guerra.

\section{CONSIDERAÇÕES FINAIS}

Como primeira consideração extraída deste estudo, achamos que, não obstante a caraterística "camaleônica" da guerra, como assegurava Clausewitz, há permanências que permitem manter a tese essencialista de que sua essência política continua definindo-a, assim como é o cálculo político que conduz a guerra e controla as operações militares.

Depois de uma análise histórica do desenvolvimento da guerra, concluímos que não se constatam fatos históricos concluintes nem suficientes para 
defender a existência de revoluções militares nem nos assuntos militares. Percebem-se, sim, mudanças na perspectiva historiográfica da "longa duração" (à la Braudel) que assimilam culturalmente tecnologias materiais e organizacionais, novas doutrinas de emprego, adequações táticas e desempenhos estratégicos. Constatamos que o impacto na condução da guerra nunca corresponde a uma novidade técnica, mas à integração de várias tecnologias combinadas na distância temporal que permite refletir sobre a doutrina geral e de emprego. Talvez por isso, dificilmente uma tecnologia é estrategicamente decisiva para aquele que a introduz, mas para quem, observando esse primeiro emprego, consegue pensar outro mais eficiente e de maneira combinada com outras tecnologias. A caraterística conservadora e tradicionalista da corporação militar, como notou Janowitz (1960), é uma das causas que talvez explique a dificuldade para uma pronta adequação doutrinária da condução da guerra às novas tecnologias.

Como se a superioridade incontestável de meios materiais ofuscasse a inteligência e sutileza estratégica, a história é fértil em exemplos que mostram que a sofisticação em desenho estratégico e seu emprego eficiente normalmente acompanham o lado mais fraco na relação de força. Isto parece reforçar a ideia contida naquele adágio de que a necessidade agudiza a inteligência. Também é a história das guerras que fornece a evidência de que não é a superioridade tecnológica do armamento per se que garante a vitória militar. Como afirmou Clausewitz, a vitória na guerra é o resultado de uma complexa equação na qual intervêm variáveis não quantificáveis, como a vontade política, a astúcia do estrategista, o moral da tropa e a capacidade de resistência de um povo.

Tanto os que reduzem as revoluções à repentina incorporação de uma nova tecnologia quanto aqueles que defendem que é precisamente essa tecnologia que definirá o resultado da guerra, ambos parecem estar mais interessados em vender armamentos do que em refletir sobre a natureza da guerra ou mesmo pensar a estratégia de como ganhar a próxima.

\section{REFERÊNCIAS}

Black, Jeremy. 1991. A Military Revolution? Military Change and European Society, 1550-1800. Hampshire: MacMillan Press.

1995. "A Militar Revolution? A 1660-1792 perspective". In: Rogers, Clifford. The Military Revolution Debate: readings on the Military Transformations of Early Modern Europe. Boulder, Westview.

Childs, John. 2001. Warfare in the Seventeenth Century. Washington: Smithsonian Books. 
Clausewitz, Carl Von. 1996. Da Guerra. São Paulo: Martins Fontes.

Creveld, Martin van. 2004. Ascensão e Declínio do Estado. São Paulo: Martins Fontes.

Fitzsimonds, James R., and Jan M. Van Tol. 1994. Revolutions in Military Affairs. Joint Force Quaterly (JFQ) (May). Washington: National Defense University.

Hall, Bert S. 1997. Weapons and Warfare in Renaissence Europe. Baltimore and London: The Johns Hopkins University Press.

Hammes, Thomas Xavier. 2006. The Sling and the Stone: on war in the $21^{\text {th }}$ century. St. Paul: Motorbooks.

Hanson, Victor Davis. 2002. Por que o Ocidente Venceu: massacre e cultura - da Grécia antiga ao Vietnã. Rio de Janeiro: Ediouro.

Headrick, Daniel R. 1981. The Tools of Empire: technology and European Imperialism in the Nineteenth Century. New York: Oxford University Press.

Hundley, Richard O. 1999. Past Revolutions, Future Transformations: what can history of the revolutions in military affairs tell us about transforming the U.S. military? Washington: National Defense Research Institute.

Jacob, Frank, and Gilmar Visoni-Alonzo. 2016. The Military Revolution in Early Modern Europe: a revision. New York: Palgrave MacMillan.

Janowitz, Morris. 1960. The Professional Soldier. New York: The Free Press, a Division of MacMillan, Inc.

Kingra, Mahinder S. 1993. The Trace Italienne and the Military Revolution During the Eighty Years' War, 1567-1648. In: The Journal of Military History, 57 (July).

Knox, MacGregor, and Williamson Murray. 2008. Thinking about revolutions in warfare. In: KNOX, MacGregor, and Murray, Williamson. The Dinamics of Military Revolution, 1300-2050. Cambridge: Cambridge University Press.

McNeill, William H. 1982. The Pursuit of Power: technology, armed force, and society since A. D. 1000. Chicago: The University of Chicago Press.

Mori, Victor Hugo. 2003. Arquitetura Militar: um panorama histórico a partir do porto de Santos. São Paulo: IMESP. 
Morillo, Stephen, and Michael F. Pavkovic. 2006. What is Military History? Cambridge: Polity Press.

Parker, Geoffrey. 2002. La Revolución Militar: innovación militar y apogeo de Occidente, 1500-1800. Madrid: Alianza Editorial.

Parker, Geoffrey. The Limits to Revolutions in Military Affairs: Maurice of Nassau, the Battle of Nieuwpoort (1600), and the Legacy. The Journal of Military History. Volume 71, Number 2, April 2007 pp. 331-372.

Piella, Guillem Colom. 2008. Entre Ares y Atena: El Debate sobre La Revolución em los Assuntos Militares. Madrid: Instituto Universitário General Gutiérrez Mellado.

Reid, Brian Holden. 1999. The American Civil War and the Wars of the Industrial Revolution. London: Cassell.

Roberts, Michael. 1995. The Military Revolution, 1560-1660. In: Rogers, Clifford J. The Military Revolution Debate: readings on the Military Transformation of Early Modern Europe. Boulder: Westview Press.

Rogers, Clifford. 1995. The Military Revolutions of the Hundred Years War. In: Rogers, Clifford. The Military Revolution Debate: readings on the Military Transformations of Early Modern Europe. Boulder, Westview.

. 2001. "As if a new sun arisen": England's fourteenth-century RMA. In: Knox, MacGregor, and Williamson Murray. The Dynamics of Military Revolution, 1300-2050. Cambridge: Cambridge University Press.

Wilkins, Warren. 2011. Grab Their Belts to Fight Them: the Viet Cong's big-unit war against the U.S., 1965-1966. Annapolis: Naval Institute Press. 


\section{NOTAS}

1. A pólvora é uma invenção chinesa datada do século X. Sua primeira fórmula escrita (chinesa) data de 1044, sendo transmitida aos árabes e europeus no século XIII, uma época de muitas trocas comerciais e culturais entre a cristandade, o Islã e o extremo oriente. Para Bert S. Hall, tal processo foi muito parecido com os projetos de transferência de tecnologia do século XX, destacando, porém, que “(...) os europeus nunca imitaram totalmente os vários usos dos chineses para a pólvora, preferindo, em vez disso, focar na mais belicosa de suas aplicações, armas." Hall também aponta que o primeiro escrito europeu a apresentar uma “(...) fórmula para uma baixa mistura de salitre, enxofre e carvão”, foi a "Epistola de secretis operibus artiis et naturae", de Roger Bacon, datada de 1267. In: HALL, Bert S. Weapons and Warfare in Renaissence Europe. Baltimore and London: The Johns Hopkins University Press, 1997, pp. 41-43).

2. Eram soldados armados com pesados fuzis, ou mosquetes, carregados pela boca e cuja pólvora era acionada por um pavio, ou mecha, que era segurado por uma presilha, conhecida como "cão", ligada a um gatilho

3. Sobre o traçado italiano: MORI, Victor Hugo. 2003. Arquitetura Militar: um panorama histórico a partir do porto de Santos. São Paulo: IMESP.

4. Caso da resistência dos etíopes contra a ocupação italiana, entre 1935 e 1942.

5. Dissemos "mal chamadas" porque todo conflito armado enfrenta pelo menos duas partes beligerantes, e se bem pode ser que o esforço bélico de uma das partes represente uma "baixa intensidade" com relação a sua capacidade bélica, para o outro beligerante o esforço pode ser total. Consideramos errôneo caracterizar uma guerra pelo esforço de apenas uma das partes ignorando o significado completo da guerra.

6. Casos das guerras na Indochina, entre 1945 e 1975. A primeira foi a luta dos comunistas vietnamitas contra os colonialistas franceses, entre 1945 e 1954; a segunda foi a luta pela unificação do Vietnã, entre os comunistas do Vietnã do Norte e o governo capitalista do Vietnã do Sul, amplamente apoiado pelos Estados Unidos, entre 1965 e 1975. 
NEM REVOLUÇÃO MILITAR (RM) NEM REVOLUÇÃO

EM ASSUNTOS MILITARES (RAM), APENAS MUDANÇAS

DE LONGA DURAÇÃO CONDENSADAS NA GUERRA PELO GÊNIO MILITAR

\section{RESUMO:}

Gerações de historiadores, desde os primórdios do século XX, detiveram-se no estudo e compreensão da transformação da guerra. Todavia, seu esforço se converteu numa mitificação do potencial da tecnologia para produzir a mudança revolucionária, social, econômica e política, além da propriamente militar. Aqui discutimos esta mitificação, tanto nas chamadas "Revoluções Militares" quanto na "Revolução dos Assuntos Militares". Apresentamos críticas bibliográficas a estas posições que também contrastamos com contraexemplos históricos. Chegamos a várias conclusões, mas, particularmente, à convicção de que não há revoluções na condução e natureza da guerra, senão mudanças que se percebem na dinâmica da "longa duração".

Palavras-Chave: Guerra; Revolução; Tecnologia.

\section{ABSTRACT:}

Generations of historians since the early twentieth century have focused on the study and understanding of the war's transformation, yet their effort has become a mythification of the potential of technology to produce revolutionary, social, economic, and political change, as well as military. Here we discuss this mythification, both in the so-called "Military Revolutions" and in the "Revolution of Military Affairs". We present bibliographical critiques to these positions that we also contrast with historical counterexamples. We come to several conclusions, but particularly to the conviction that there are no revolutions in the conduct and nature of war other than changes that are perceived in the dynamics of "long duration".

Keywords: War; Revolution; Technology. 